\title{
Under pressure: another clinical scenario
}

\author{
Narinder Pal Singh, MD, PDCC • Jeetinder Kaur Makkar, MD, DNB, MNAMS • \\ Vincent Wourms, MD, FRCPC $\cdot$ Ron B. Cappellani, MD, FRCPC
}

Received: 2 July 2018/Revised: 5 August 2018/Accepted: 10 October 2018/Published online: 22 October 2018

(C) Canadian Anesthesiologists' Society 2018

\section{To the Editor,}

Miao et al. recently conducted an audit and found that cuff pressure was higher than recommended in 33 of 113 (29\%) endotracheal tubes and eight of 14 (57\%) supraglottic airways. ${ }^{1}$ We agree with the 58 of 66 respondents $(88 \%)$ who would use a cuff manometer more frequently if it were more readily available in each operating room. We report another clinical scenario to emphasize the importance of measuring cuff pressures.

Extubation of the trachea and emergence from general anesthesia can lead to many undesirable effects, including tachycardia, hypertension, raised intracranial and intraocular pressures, coughing, bronchospasm, and surgical bleeding. Inflation of the tracheal tube cuff with alkalized lidocaine allows slow diffusion of the drug into the tracheal mucosa, thereby attenuating the extubation response as well as decreasing the incidence of sore throat. $^{2,3}$

Continuous diffusion of lidocaine from the cuff reservoir reduces cuff volume and the potential for a leak to develop around the tube. The leak can range from a

N. P. Singh, MD, PDCC ( $)$ - V. Wourms, MD, FRCPC .

R. B. Cappellani, MD, FRCPC

Department of Anesthesia and Perioperative Medicine, Health

Sciences Centre, University of Manitoba, Winnipeg, MB,

Canada

e-mail: nscjk2006@gmail.com

J. K. Makkar, MD, DNB, MNAMS

Department of Anesthesia, Post Graduate Institute of Medical

Education and Research, Chandigarh, India small bubbling breath sound to a clinically significant loss of tidal volume. Tracheal aspiration of gastric or pharyngeal secretions due to this leak may lead to postoperative respiratory complications.

We suggest that intermittent cuff pressure measurement should also be done in all patients whose tracheal tubes are inflated with lidocaine. In addition, the cuffs of endotracheal tubes should be lubricated with watersoluble gel, which will assist in filling the longitudinal channels around the cuff. This may assist in maintaining the desired minute ventilation, decrease the leakage of anesthetic gases from the trachea, and decrease the incidence of micro aspiration without compromising the diffusion of lidocaine across the tracheal mucosa. ${ }^{4,5}$

Anesthesiologists should remain vigilant for cuff leaks when using lidocaine filled cuffs and be prepared to access the pilot balloon and measure cuff pressures when using this technique.

Conflicts of interest None declared.

Editorial responsibility This submission was handled by Dr. Gregory L. Bryson, Deputy Editor-in-Chief, Canadian Journal of Anesthesia.

\section{References}

1. Miao I, Jee R, Pysyk CL. Under pressure: an audit of airway device pressures. Can J Anesth 2018; 65: 726-7.

2. Lam F, Lin YC, Tsai HC, Chen TL, Tam KW, Chen $C Y$. Effect of intracuff lidocaine on postoperative sore throat and the emergence phenomenon: a systematic review and meta-analysis of randomized controlled trials. PLoS One 2015; 19: e0136184. 
3. Estebe JP, Dollo G, Le Corre P, et al. Alkalinization of intracuff lidocaine improves endotracheal tube-induced emergence phenomena. Anesth Analg 2002; 94: 227-30.

4. Blunt MC, Young PJ, Patil A, Haddock A. Gel lubrication of the tracheal tube cuff reduces pulmonary aspiration. Anesthesiology 2001; 95: 377-81.
5. Estebe JP, Delahaye $S$, Le Corre P, et al. Alkalinization of intracuff lidocaine and use of gel lubrication protect against tracheal tube-induced emergence phenomena. Br J Anaesth 2004; 92: 361-6. 